\title{
Characterization of Stigma Exudates in Aqueous Extracts from Apple and Pear Flowers
}

\author{
P. Lawrence Pusey ${ }^{1,3}$, David R. Rudell ${ }^{2}$, Eric A. Curry ${ }^{2}$, and \\ James P. Mattheis ${ }^{2}$ \\ U.S. Department of Agriculture, Agricultural Research Service, Tree Fruit \\ Research Laboratory, 1104 North Western Avenue, Wenatchee, WA 98801- \\ 1230
}

Additional index words. Pyrus communis, Malus pumila, Malus mandshurica, Erwinia amylovora, Rosaceae

\begin{abstract}
The stigmatic secretions of pomaceous flowers serve as a natural medium not only for pollen, but also for the pathogen Erwinia amylovora (Burr.) Winslow et al. and other microorganisms. To understand the microecology on the stigma, exudates from cultivars of pear (Pyrus communis L.), apple (Malus pumila P. Mill.), and crab apple [Malus mandshurica (Maxim.) Kom.] were analyzed for free sugars and free amino acids as available carbon and nitrogen sources. Extracts were obtained at different stages of anthesis by submerging and sonicating stigmas in water. Certain free sugars (glucose and fructose) and free amino acids (proline, asparagine, glutamic acid, and glutamine) were consistently predominant and increased during anthesis. Apple stigma extracts were also analyzed for polysaccharides and proteins. Of major components identified for apple, free sugars made up $4.5 \%$ by mass; polysaccharides (composed of arabinose and galactose), $49.6 \%$; and proteins, $45.9 \%$. The two largest components are likely present as glycoproteins. This may be the first report on characteristics of rosaceous stigma exudates that includes the identity of specific free sugars, free amino acids, and polysaccharide subcomponents. Discussion includes the comparison of pomaceous stigma exudates to those of other plants and the microecological implications.
\end{abstract}

Given the importance of the stigma to fruit development in agriculturally prominent species in Rosaceae, there is surprisingly little information about the composition of stigma exudates of plants in this group. Although such data are extensive for a number of other flowering plants (Knox, 1984), studies involving rosaceous species are limited to histological investigations indicating the general presence of intercellular carbohydrates, proteins, and lipids in stigmatic tissue (Cresti et al., 1980; Stant, 1981; Uwate and Lin, 1981) and to the recent focus on S-RNases (Certal et al., 1999; Ishimizu et al., 1996; McClure and FranklinTong, 2006; Sonneveld et al., 2005). The deficiency of information for tree fruit species may be partly the result of the relatively small size of stigmas and brevity of the bloom period.

The stigma exudates of flowering plants serve as a natural medium for pollen germination and other functions in the pollenstigma interaction (Heslop-Harrison, 2000;

\footnotetext{
Received for publication 25 Feb. 2008. Accepted for publication 3 Apr. 2008.

We thank Janet Duffy, Brenda Steady, and Dave Buchanan for technical assistance and Van Well Nursery for providing trees.

${ }^{1}$ Research Plant Pathologist.

${ }^{2}$ Research Plant Physiologist.

${ }^{3}$ To whom reprint requests should be addressed; e-mail larry.pusey@ars.usda.gov
}

Knox, 1984). Exudates produced by flower stigmas of pome fruit trees are also an excellent medium for many microorganisms (Pusey, 1997, 1999b; Stockwell et al., 1999). Pomaceous stigmas and their exudates not only sustain a wide diversity of bacteria, yeasts, and other fungi, but they also support microbial population densities far exceeding those of most other aerial plant surfaces. In a review by Johnson and Stockwell (1998), this point was illustrated by comparing maximum bacterial populations on bean leaves to those on pear stigmas. Pseudomonas syringae pv. syringae is reported to attain populations of $\approx 10^{6}$ colony-forming units (cfu) per gram fresh weight of bean leaves (Beattie and Lindow, 1994), but the carrying capacity of bacteria on pear stigmas is estimated at $10^{9}$ to $10^{10} \mathrm{cfu} / \mathrm{g}$. Another unique aspect of the stigma as a microbial habitat is its frequent contact with pollinating insects that carry microorganisms from flower to flower (Johnson et al., 1993; Thomson et al., 1992; Vanneste, 1996).

Microbial colonization on stigmas has been given considerable attention in connection with fire blight, a serious disease of apple, pear, and other rosaceous plants. The stigma is the primary site supporting establishment of the causal bacterium, Erwinia amylovora (Burr.) Winslow et al. (Johnson and Stockwell, 1998). Typically, epiphytic populations increase on stigmas during warm periods but usually do not cause disease until rain or dew facilitates movement of the pathogen from the stigma to the hypanthium where infection occurs through nectarthodes (Thomson, 1986). Erwinia amylovora appears to be well adapted epiphytically to the stigmatic surfaces of even nondiseasehost rosaceous species (Johnson et al., 2006). As an alternative to the use of antibiotics for suppression of E. amylovora on apple and pear blossoms, researchers have evaluated other naturally occurring microbial residents on flowers as potential biological control agents for fire blight (Johnson and Stockwell, 2000). Beneficial strains exhibiting antagonism toward E. amylovora suppress the pathogen by competing for space and nutrients and producing antibiotic compounds. In 1996, Pseudomonas fluorescens (Trevison) Migula strain A506 was the first microbial agent to become available commercially for fire blight management (Johnson and Stockwell, 2000). Others have since been developed, and in at least one case, farm managers are given the option of delivering the product to flowers using honeybees (Vanneste, 1996; Vanneste et al., 2002).

Knowledge of the biochemistry of stigma exudates is not only a prerequisite to understanding pollen-stigma interactions (Kandasamy and Vivekanandan, 1986; Knox, 1984), but it is necessary for understanding microbial interactions that may be advantageous for preventing fire blight of apple and pear. Chemical analyses of the pomaceous exudates provide basic information related to reproduction in an important plant group not yet given such attention and may reveal major nutrient sources supporting both disease-causing and beneficial microorganisms on stigmas. The latter objective was the primary motivation for the current study. Stigma exudates from apple and pear at different stages of anthesis were first analyzed for free sugars and free amino acids that may serve as available carbon and nitrogen sources for microbial activity. Further analyses were performed with apple to identify other major components of the exudates.

\section{Materials and Methods}

Extraction procedure. Stigma exudates were collected from flowers of pear (Pyrus communis L.) and apple (Malus pumila $\mathrm{P}$. Mill.) in 2003 and 2004. Tree cultivars were 'Anjou' and 'Bartlett' pear and 'Fuji,' 'Gala', and 'Golden Delicious' apple, all located in research orchards near Wenatchee, WA. Blossoms were not protected from indigenous microorganisms or insect visitors during the sampling period. Crab apple [Malus mandshurica (Maxim.) Kom.], maintained in a greenhouse and used routinely as a source of blossoms for laboratory assays (Pusey, 1997), was evaluated along with apple and pear cultivars in 2004. Flowers were sampled at three stages based on anther dehiscence: nondehisced, $40 \%$ to $60 \%$ dehisced, and $100 \%$ dehisced. For each cultivar and stage per year, a minimum of two groups of 50 flowers was sampled. Each 

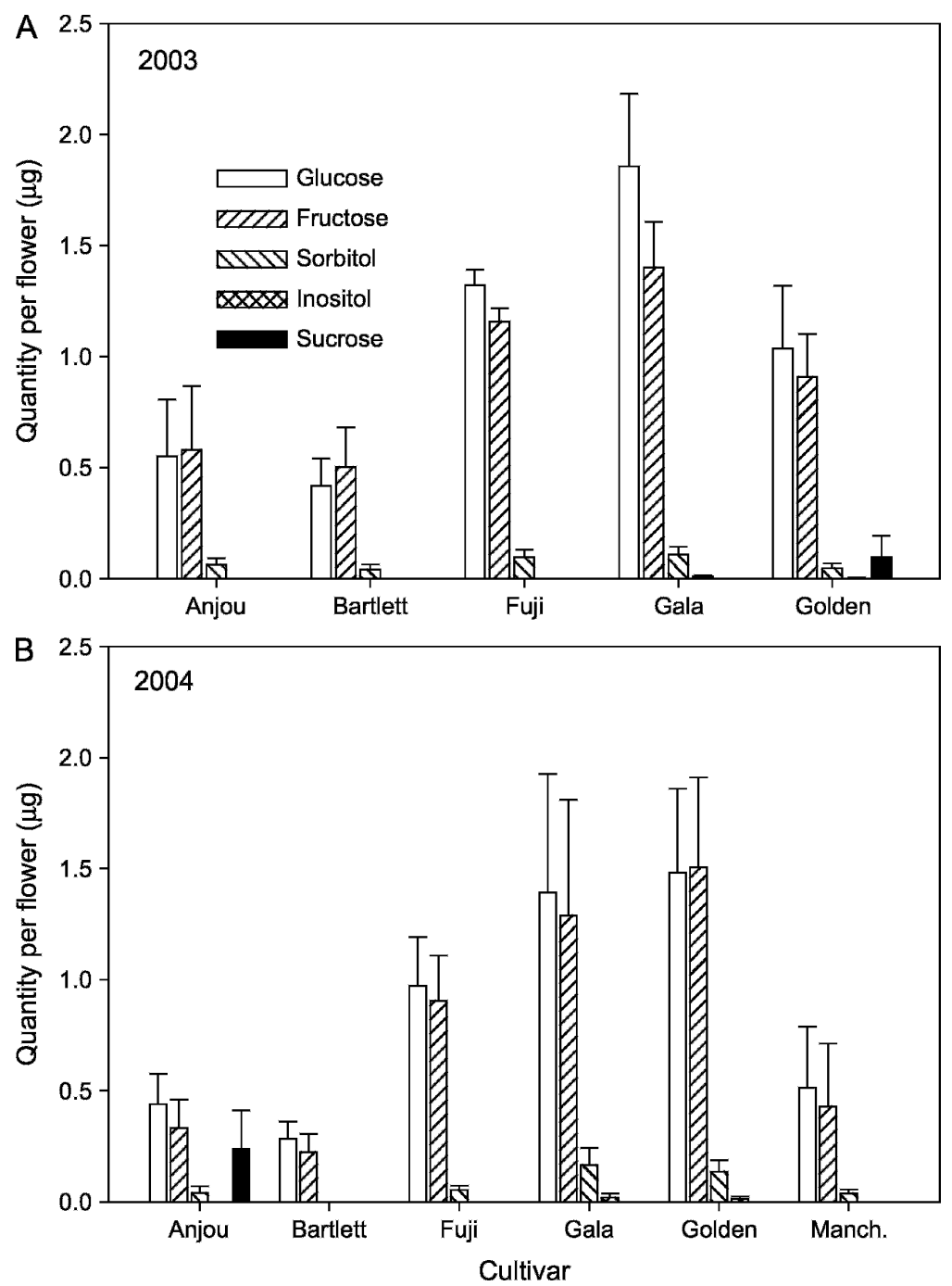

Fig. 1. Free sugars detected in stigma exudates from 'Anjou' and 'Bartlett' pear (Pyrus communis); 'Fuji', 'Gala', and 'Golden' apple (Malus pumila) and 'Manchurian' crab apple (Malus mandshurica) in (A) 2003 and (B) 2004. Each bar represents mean $( \pm \mathrm{SE})$ of at least six samples, each derived from 50 flowers.

excised flower was temporarily maintained with cut pedicel supported in a $2-\mathrm{mL}$ vial filled with water. The flowers were transported to the laboratory where either stigma exudates were collected the same day or flowers were held overnight at 1 or $2{ }^{\circ} \mathrm{C}$ before extracting exudates. Anthers were removed and stigma tips of 50 flowers were submerged, one flower at a time, in the same volume of $600 \mu \mathrm{L}$ water held in a microfuge tube while sonicated for $10 \mathrm{~s}$ per flower. Pollen, debris, and microorganisms were removed from the aqueous solution by centrifugation at $16,000 g_{\mathrm{n}}$ for $5 \mathrm{~min}$ and by subsequent filtration of supernatant in a syringe-driven unit with a PVDF membrane, 4-mm diameter and $0.22-\mu \mathrm{m}$ pore size (Millex-GV; Millipore Corp., Billerica, MA). Macromolecules were eliminated by filtration in centrifugal devices, the first with a $100-\mathrm{kDa}$ cutoff and a second one with a $3-\mathrm{kDa}$ cutoff (Nanosep $100 \mathrm{~K}$ and $3 \mathrm{~K}$ Omega; Pall Corp., Ann Arbor, MI). Filtrates were stored at $-20{ }^{\circ} \mathrm{C}$ until analyses were performed.
To substantiate how the free sugar composition of stigma exudates compares with nectar sugar composition, which has already been documented for apple and pear (Bieleski and Redgwell, 1980; Campbell et al., 1990; Wykes, 1952), flowers sampled in 2004 for stigma exudate analyses were also evaluated for nectar sugars. Nectar was collected from the hypanthium of each flower with a micropipet, and then pooled samples from each group of 50 flowers were analyzed for sugars using the procedure described below for stigma exudates.

Sugar analysis. Sugars were converted to trimethylsilyl derivatives before gas chromatography (GC) analysis using the method of Mateo et al. (1987) with the main modification involving preparation of keto groups with methoxyamine hydrochloride to prevent multiple derivatives from forming during silylation (Horning et al., 1968). To $150 \mu \mathrm{L}$ of stigma sample, $20 \mu \mathrm{g}$ (in $20 \mu \mathrm{L}$ ) of phenyl $\beta$-D-glucose was added as an internal standard, and the extract was concentrated to dryness with a vacuum evaporator (Savant
Speed Vac Concentrator; Savant Instruments Inc., Holbrook, NY). Afterward, $5 \mu \mathrm{L}$ 2dimethylaminoethanol and $125 \mu \mathrm{L}$ methoxyamine hydrochloride in pyridine $(20$ $\mathrm{mg} \cdot \mathrm{mL}^{-1}$ ) were added to the dry extract, and the solution was heated at $85^{\circ} \mathrm{C}$ for $1 \mathrm{~h}$. After cooling to room temperature, $125 \mu \mathrm{L}$ hexamethyldisilazane and $5 \mu \mathrm{L}$ trifluoroacetic acid were added. The sample solution was centrifuged for $5 \mathrm{~min}$ at $5900 \mathrm{~g}_{\mathrm{n}}$, then the clear supernatant was withdrawn and transferred to a GC vial.

The analyses were performed with an Agilent Model 6890N GC (Agilent Technologies, Palo Alto, CA) equipped with a flame ionization detector. One microliter of each sample was injected on a $2.5 \%$ phenyl methyl siloxane capillary column $(25 \mathrm{~m} \times 0.2 \mathrm{~mm}$ i.d., $\quad 0.33-\mu \mathrm{m}$ film thickness; Agilent 19091B-102E). Hydrogen was used as the carrier gas at a flow rate of $0.5 \mathrm{~mL} \cdot \mathrm{min}^{-1}$. The injector temperature was held at $250{ }^{\circ} \mathrm{C}$ in the split mode (split ratio 50:1). The column oven temperature started at $180^{\circ} \mathrm{C}$ for $2 \mathrm{~min}$, increased to $240{ }^{\circ} \mathrm{C}$ at $10{ }^{\circ} \mathrm{C} \cdot \mathrm{min}^{-1}$, held at $240{ }^{\circ} \mathrm{C}$ for $3.5 \mathrm{~min}$, increased to $270{ }^{\circ} \mathrm{C}$ at $30{ }^{\circ} \mathrm{C} \cdot \mathrm{min}^{-1}$, and held at $270{ }^{\circ} \mathrm{C}$ for $12 \mathrm{~min}$. Identification and quantification of sugars were based on retention times and peak areas, respectively, of reference sugars (SigmaAldrich Co., St. Louis, MO).

Amino acid analysis. Amino acids were converted to derivatives with $o$-phthaldialdehyde (OPA) and 9-fluorenylmethoxycarbonyl chloride (FMOC) using the method of Herbert et al. (2000), with several minor modifications, before analysis by high-performance liquid chromatography (HPLC). The HPLC system consisted of model HP1090L (Hewlett Packard Co., Rancho Bernardo, CA) fitted with a HypersilAA column (Agilent 79916AA) and a tunable fluorescence detector (HP1046A; Hewlett Packard Co.). For derivatization of primary amino acids, $5 \mu \mathrm{L}$ of $0.4 \mathrm{~N}$ borate buffer ( $\mathrm{pH}$ 10.2) $1 \mu \mathrm{L}$ OPA reagent (Agilent $\mathrm{p} / \mathrm{n}$ 50613337 ), and $1 \mu \mathrm{L}$ of the extract were introduced into the sample loop and allowed to mix. Secondary amino acids were subsequently derivatized by adding $1 \mu \mathrm{L}$ FMOC reagent (Agilent $\mathrm{p} / \mathrm{n}$ 5061-3337) to the system. After derivatization, which required less than $2 \mathrm{~min}, 1 \mu \mathrm{L}$ of the sample mixture was injected into the column.

A gradient mobile phase consisted of solvent $\mathrm{A}$ and $\mathrm{B}$ at an initial flow rate of $0.45 \mathrm{~mL} \cdot \mathrm{min}^{-1}$. Solvent A was $20 \mathrm{~mm}$ sodium acetate buffer $(\mathrm{pH} 7.2)$ with $0.018 \%(\mathrm{v} / \mathrm{v})$ triethylamine and $0.3 \%$ tetrahydrofuran. Solvent $\mathrm{B}$ was $20 \%$ mm sodium acetate buffer (pH 7.2), 40\% acetonitrile, and 40\% methanol. The ratio of solvent A to B changed from $100 \%$ to $40 \%$ within $17 \mathrm{~min}$ declining to solvent $\mathrm{B}$ alone during the next minute. The flow rate was then ramped to $0.8 \mathrm{~mL} \cdot \mathrm{min}^{-1}$ in $0.5 \mathrm{~min}$ and held at this rate for $4.5 \mathrm{~min}$ before returning to $0.45 \mathrm{~mL} \cdot \mathrm{min}^{-1}$. Amino acids were detected by a fluorescence spectrophotometer with excitation and emission wavelengths set at 340 and $450 \mathrm{~nm}$, respectively, for the first $15 \mathrm{~min}$ and then adjusted to 
266 and $305 \mathrm{~nm}$, respectively. An amino acid standard mix (Agilent Technologies) was used for obtaining qualitative and quantitative information.

Other stigma analyses. Stigma exudates of apple flowers at $40 \%$ to $60 \%$ anther dehiscence were analyzed in 2004 for total carbohydrates, proteins, and lipids. Each sample was derived from 50 flowers as already described, except filtration was performed only with membranes of $0.22-\mu \mathrm{m}$ pore size and not with devices designed to block macromolecules.

Carbohydrates in five 'Fuji' and five 'Gala' samples were hydrolyzed using the method of Goubet et al. (2002) and then analyzed for monosaccharides. A $50-\mu \mathrm{L}$ aliquot from each $600-\mu \mathrm{L}$ sample was heated at $100{ }^{\circ} \mathrm{C}$ for $2 \mathrm{~h}$ in $0.5 \mathrm{~mL}$ of $2 \mathrm{M}$ trifluoroacetic acid, dried in a vacuum evaporator, and put through three methanol wash and dry cycles. It was then subjected to derivatization and GC as described for sugar analysis.

Protein quantities in seven 'Fuji' samples and nine 'Gala' samples were estimated by the method of Bradford (1976) using a kit obtained from Sigma Diagnostics (St. Louis, MO). A 50- $\mu \mathrm{L}$ aliquot per sample was tested. Protein standards from human albumin were prepared at $0.5,1,2$, and $3 \mathrm{mg} \cdot \mathrm{mL}^{-1}$.

The aqueous stigma samples were evaluated for the presence of lipids by GC analysis of fatty acid methyl esters (Moss, 1981) using procedures specified in the Sherlock Microbial Identification System (MIDI, Newark, DE). This was done with three 'Fuji' and two 'Gala' samples. The $600-\mu \mathrm{L}$ samples were dried in a vacuum evaporator before esterification. GC equipment was the same as that used for sugar analysis, and GC conditions were set by MIDI software for eukaryotic cells (EUKARY Version 3.71).

Data analyses. Means and SE were calculated for quantities of specific components detected in exudates extracted from the pomaceous stigmas. Comparisons of total free sugars and amino acids from flowers at different stages of anthesis were done by linear regression and $t$ tests for two group means using SAS v.9.1 software (SAS Institute, Cary, NC).

\section{Results}

During flower sampling from the apple and pear orchard site, daily high and low temperatures averaged 18.7 and $5.5^{\circ} \mathrm{C}$ in 2003 and 22.2 and $3.3{ }^{\circ} \mathrm{C}$ in 2004 . Only a trace amount of rain was recorded on $1 \mathrm{~d}$ in 2003 and no rain was detected in 2004. Rate of flower development and senescence was similar in the 2 years. When flowers were newly opened, stigmas appeared light green, and anthers were bright yellow and none dehisced. At 4 or $5 \mathrm{~d}$ after petal expansion, when anthers were fully dehisced, stigmas had begun changing from light green to yellow, and petals were beginning to drop. Flowers were generally not collected beyond 5 or $6 \mathrm{~d}$ after petal expansion.
At each stage of anther dehiscence, free sugars in stigma exudates from pear, apple, and crab apple flowers were predominately glucose and fructose in near equal proportions with only trace amounts of sucrose (Fig. 1). One exception involved 2004 samples from 'Anjou' pear in which the sucrose portion approached that of monosaccharides (Fig. 1B). Also detected in stigma exudates were low or trace amounts of sorbitol and inositol. Monosaccharides detected in stigma exudates appeared to increase with flower age as indicated by the progression of anther dehiscence (Fig. 2). Average total quantities of monosaccharides extracted from pear stigma exudates ranged from $0.31 \mu \mathrm{g}$ per flower at early anthesis $(0 \%$ anther dehiscence) to $1.27 \mu \mathrm{g}$ per flower at late anthesis (100\% dehiscence); monosaccharide quantities for apple at early and late anthesis were 1.87 and $3.19 \mu \mathrm{g}$ per flower. The data did not fit the linear regression model $\left(r^{2}<0.25\right)$; however, $t$ test comparisons of monosaccharide quantities for early and late anthesis revealed differences at $P<0.1$ for pear $(P=$ $0.08)$ and apple $(P=0.06)$.

When free sugars in nectar were analyzed in 2004, quantities were a higher magnitude than those indicated for stigma exudates (Fig. 3), as expected, given that nectar secretions are generally present in far greater volumes than are stigma exudates. The amount of sucrose detected in pear nectar was very low relative to monosaccharides; in apple nectar, however, the sucrose level approached that of individual monosaccharides.

Analyses of free amino acids in stigma exudates showed similar results in 2003 (data not presented) and 2004, indicating totals of less than $1 \mathrm{pg}$ extracted per flower. Levels were comparable among cultivars of the same species (data not presented), but values for pear and apple were of a different magnitude. In 2004, total free amino acids from pear flowers at $0 \%, 40 \%$ to $60 \%$, and $100 \%$ anther dehiscence averaged $28( \pm 22)$, $18( \pm 1)$, and $46( \pm 19)$ femtograms $(\mathrm{fg})$ per
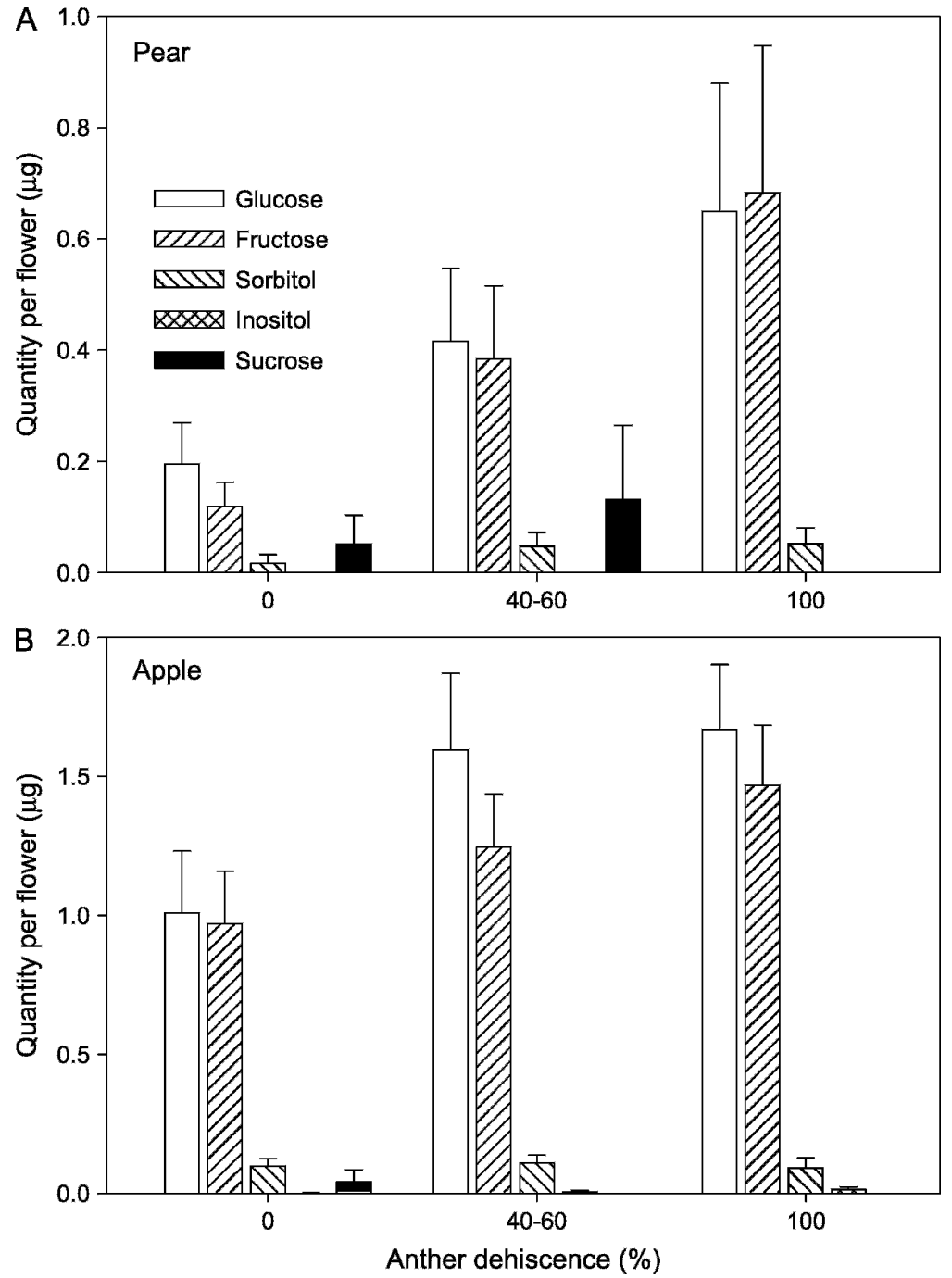

Fig. 2. Free sugars detected in stigma exudates from (A) pear (Pyrus communis) and (B) apple (Malus pumila) flowers at three stages of anthesis based on anther dehiscence in 2003 and 2004. Each bar represents mean $( \pm \mathrm{SE})$ of seven to nine pear samples or 14 to 16 apple samples, each derived from 50 flowers. 

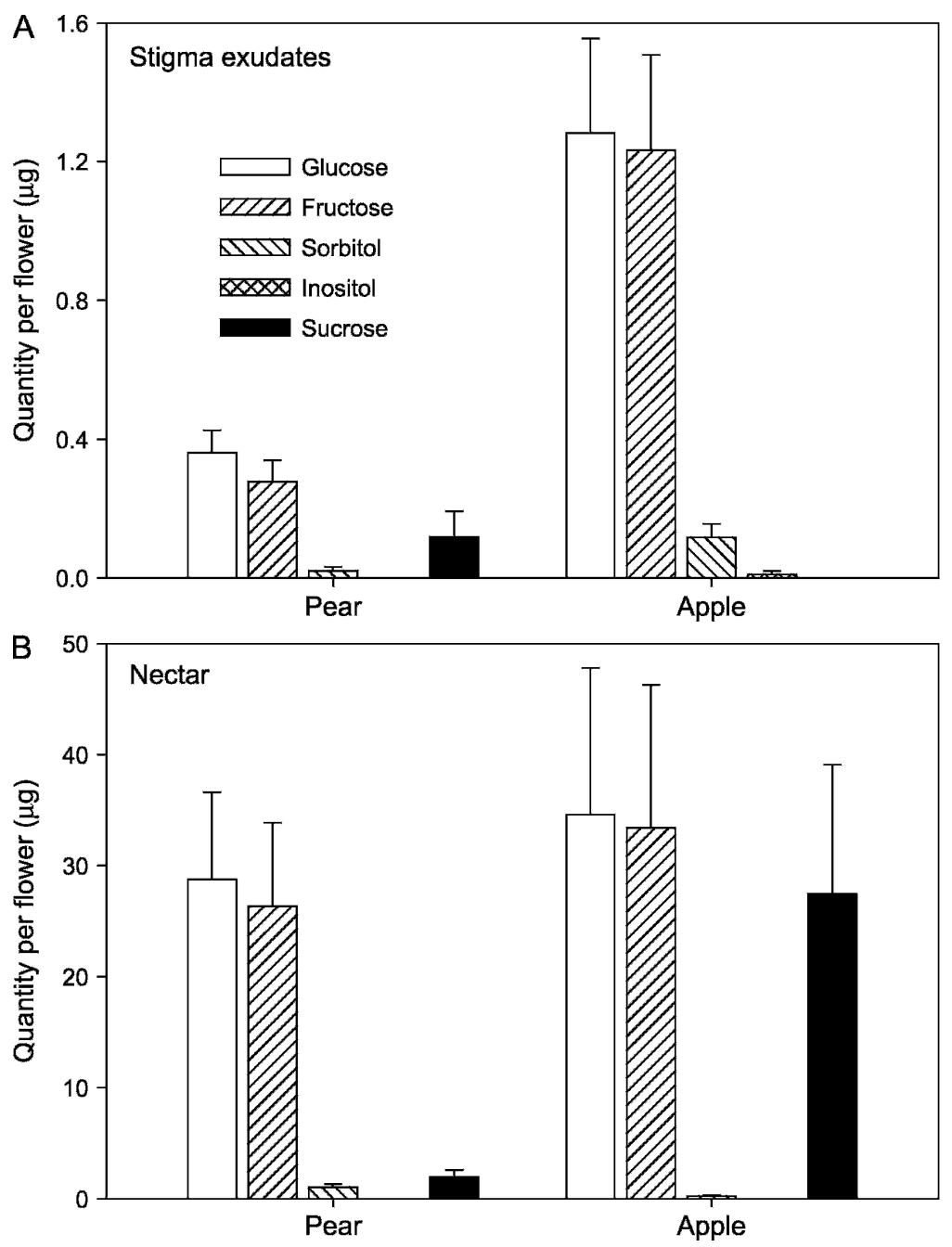

Fig. 3. Comparison of free sugar quantities in (A) stigma exudates and (B) nectar from pear (Pyrus communis) and apple (Malus pumila) in 2004. Each bar represents mean $( \pm \mathrm{SE})$ of 12 pear samples or 18 apple samples, each derived from 50 flowers.

flower, respectively; amino acids from apple flowers at these stages averaged $118( \pm 25)$, $347( \pm 5)$, and $641( \pm 125) \mathrm{fg}$ per flower, respectively; and those from 'Manchurian' crab apple, represented by single samples at each flower stage, were 20,99 , and 84 fg per flower, respectively. In the case of apple, which involved more replicate samples and higher levels of detectible free amino acids, linear regression analysis data showed that total quantities of amino acids in stigma exudates increased during anthesis $(P=$ $0.0002 ; r^{2}=0.59$ ). For all flower types, the predominant free amino acids in stigma exudates were proline, asparagine, glutamine, glutamic acid, and serine (Fig. 4); quantities of these specific amino acids extracted per flower at different stages of anthesis are presented in Figure 5. For apple, the increase of predominant amino acids as a group during anthesis was significant according to linear regression $\left(P<0.0001 ; r^{2}=0.69\right)$ and a $t$ test comparison of early and late anthesis $(P=0.0002)$.

Additional analyses were performed to assess the general presence of carbohydrates, proteins, and lipids in stigma exudates using 'Fuji' and 'Gala' apple flowers at $40 \%$ to
$60 \%$ anther dehiscence. When samples were hydrolyzed and evaluated for sugars, results with both cultivars indicated a predominance of galactose and arabinose (Fig. 6). For 'Fuji', the ratio of galactose to arabinose was 1.43, and for 'Gala', it was 1.54. The only other sugars detectable in the hydrolyzed samples were glucose and fructose; of these, glucose was most prevalent, detectable at levels exceeding those in nonhydrolyzed samples. Total polysaccharides in samples were estimated by subtracting free sugar quantities detected in nonhydrolyzed samples (Table 1). According to these estimates and results of the Bradford tests for protein, quantities of polysaccharides and proteins in exudate samples from 'Fuji' were approximately twice those for 'Gala' (Table 1). Nevertheless, ratios of polysaccharide to protein in extracts from the two cultivars were similar; 1.10 for 'Fuji' and 1.14 for 'Gala'. No lipids were detected in the aqueous

\section{Discussion}

The quantities of chemical components detected in aqueous extracts from the pomaextracts. ceous flowers in this study may not represent total amounts present on stigmas, but reflect differences depending on species and stage of anthesis. When flower stigmas were sonicated for longer than $10 \mathrm{~s}$, levels detected increased (data not presented); it is unknown, however, whether the sonication procedure removes substances primarily from the stigmatic surfaces or forces additional material from secretory cells. Furthermore, some extracted substances may have been associated with pollen, although pollen grains were separated from extraction samples after sonication.

The predominant free sugars detected on three species of pomaceous flowers were clearly glucose and fructose (Fig. 1). Sucrose was detected only in trace amounts, with the exception of 'Anjou' pear in 2004, when sucrose represented $31 \%$ of sugar detected in the exudates. Among the three plant species studied, sugar quantities detected were highest for apple followed by crab apple and pear. These differences are likely due in part to differences in stigma size and surface area; stigmas of apple are visibly the largest and those of pear are the smallest.

Before stigma exudates were analyzed for free sugars, we predicted that sucrose would be identified as a major component, since sucrose is generally a significant part of apple nectar (Campbell et al., 1990) and sometimes prevalent in pear nectar (Bieleski and Redgwell, 1980). Nectar sugars from apple were shown to have a sucrose-hexose ratio of 0.4 , comparable to ratios reported by Campbell et al. (1990). Only trace amounts of sucrose were detected in pear nectar, however, as consistent with a report by Wykes (1952). Concurrent analysis of free sugars in stigma exudates and nectar from the same flowers validated that sucrose is generally absent in stigma exudates of pomaceous flowers but present as a major component of the nectar, particularly in apple blossoms. Free sugars in nectar had a total mass of between $10 \times$ and $100 \times$ that in stigma exudates. The hypanthial surface where nectar is present likely is a less favorable habitat for bacteria than the stigma because nectar sugar concentrations vary widely, as dependent on moisture conditions (van der Zwet and Keil, 1979); dry conditions lead to increased sugar concentrations and osmotic pressure, causing a cessation of bacterial growth or decline in viable cell numbers (Ivanoff and Keitt, 1941; Pusey, 1999a, 2000).

The quantities of free amino acids detected were extremely low, relative to sugar levels, yet there was consistency regarding the predominance of certain amino acids for each plant species (Fig. 4). Proline or asparagine was predominant followed by lower amounts of glutamic acid, glutamine, and serine.

As flowers progressed through anthesis, the relative composition of free sugars and free amino acids remained the same but changed quantitatively (Figs. 2 and 5); in general, predominant sugars and amino acids during early anthesis increased and were similarly predominant in late anthesis. 

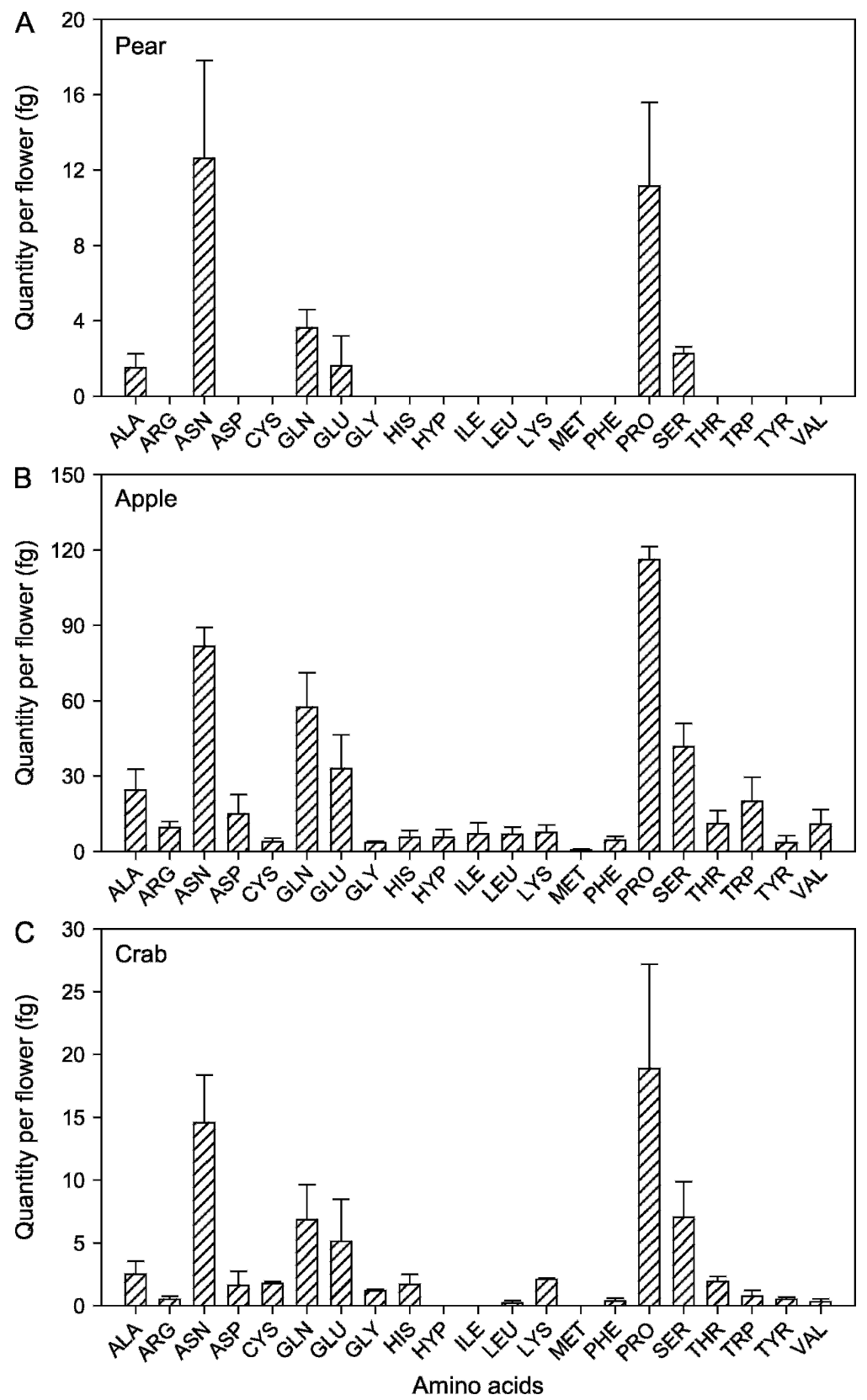

Fig. 4. Free amino acids detected in stigma exudates from (A) pear (Pyrus communis), (B) apple (Malus pumila), and (C) crab apple (Malus mandshurica) in 2004. Each bar represents mean ( $\pm \mathrm{SE})$ of six pear samples, 18 apple samples, or three crab apple samples, each derived from 50 flowers.

Stigmas of rosaceous tree species have been described as having a wet surface, papillate receptive cells, and moderate to slight secretions that flood interstices (Heslop-Harrison, 1976; Knox, 1984). Exudates of apple and pear are present on stigmas from the time flowers first open, apparently originating from cells beneath the papillate epidermis, and subsequently emanating also from the papillae (Heslop-Harrison, 1976; Sanzol et al., 2003). Although histochemical studies indicate the presence of carbohydrates and proteins in rosaceous exudates (Cresti et al., 1980; Stant, 1981), more specific information has been lacking with the exception of recent attention to S-RNases (Certal et al., 1999; McClure and Franklin- large portion of these components, if not all, are in the form of glycoproteins given the frequency of these substances in stigma exudates of other plants (Knox, 1984). Major subcomponents were arabinose and galactose, which are reported often as constituents of glycoproteins in plants, including the arabinogalactan proteins studied extensively as constituents of stigma exudates of Nicotiana alata (Cheung and $\mathrm{Wu}, 1999$; Wu et al., 2001). Although levels of free amino acids in apple and pear stigma exudates were very low (Fig. 4), the predominance of proline may be further evidence of glycoproteins, which are often rich in proline or hydroxyproline (Cheung and $\mathrm{Wu}, 1999)$. Other predominant free amino acids in the pomaceous exudates are also among those reported to be at highest levels in glycoproteins on stigmas of Nicotiana (Gane et al., 1995) and Brassica (Nishio and Hinata, 1979). The polysaccharide and protein in extracted stigma exudates from apple may represent variant forms of glycoproteins, including S-RNases (Certal et al., 1999), that possibly interact to perform multiple functions (Cheung and $\mathrm{Wu}, 1999$ ).

Lipids are often a major component of stigma exudates (Kandasamy and Vivekanandan, 1986; Knox, 1984) and may even be required for directing pollen-tube growth (WoltersArts et al., 1998). If lipids are present in apple stigma exudates, as indicated by histochemical studies (Cresti et al., 1980; HeslopHarrison, 1976; Stant, 1981), perhaps they were not separated from the stigmatic surface by the water extraction method we used (Table 1). It is also possible that quantities of lipids exuded to the surface are relatively low. Stigma exudates of Gladiolus gandavensis, which consist of arabinogalactan proteins as the major component (Gleeson and Clarke, 1979), had a detectible lipid content of less than $0.1 \%$ (Knox, 1984). In a study with Aptenia cordifolia (Kristen et al., 1979), which produces stigma exudates with some of the same carbohydrate and protein characteristics as identified for apple, lipids were not detected. Phenolic compounds are another component of plant stigma exudates (Kandasamy and Vivekanandan, 1986; Knox, 1984), but analyses for these substances were not performed in the present study.

Although free glucose and fructose are minor constituents of the stigma exudates, in terms of mass, these sugars are probably major carbon sources for microbial growth and metabolic activity on pomaceous flowers. On stigmas of individual apple flowers, free monosaccharide quantities available to bacteria are estimated at greater than $3 \mu \mathrm{g}$ by the time anthers are fully dehisced (Fig. 2). This is sufficient to support maximum bacterial growth on stigmas, known to be between $10^{6}$ and $10^{7} \mathrm{cfu}$ per flower (Johnson and Stockwell, 1998) as judged by the relationship of sugar to bacterial yields in enriched laboratory media. The current analyses indicate also that glucose and fructose are increasing on the stigma at the same time that microbial colonies are growing and 

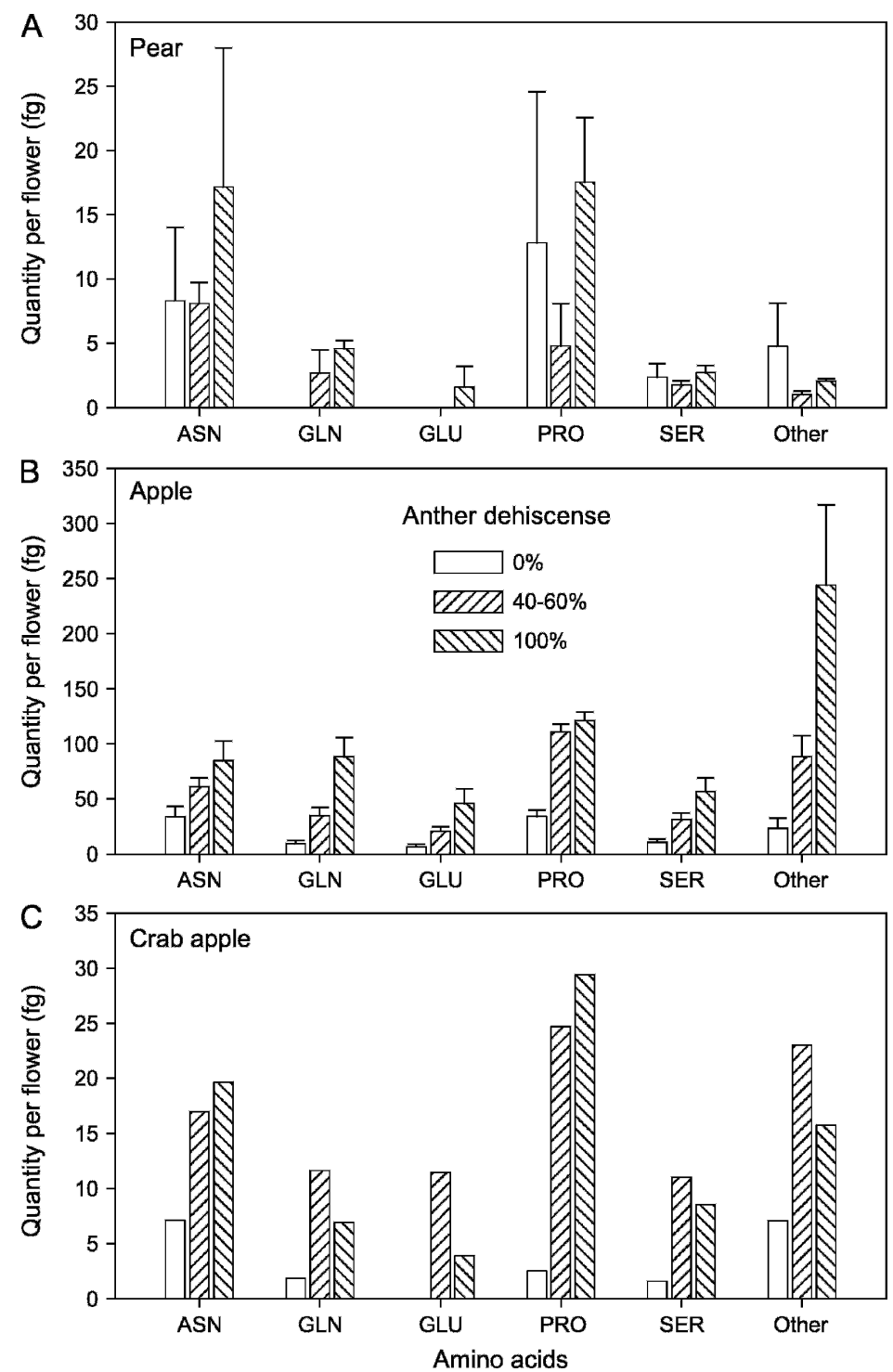

Fig. 5. Free amino acids detected in stigma exudates from (A) pear (Pyrus communis), (B) apple (Malus pumila), and (C) crab apple (Malus mandshurica) flowers at three stages of anthesis based on anther dehiscence in 2004. Each bar represents mean ( \pm SE) of two pear samples, six apple samples, or one crab apple sample, each derived from 50 flowers.

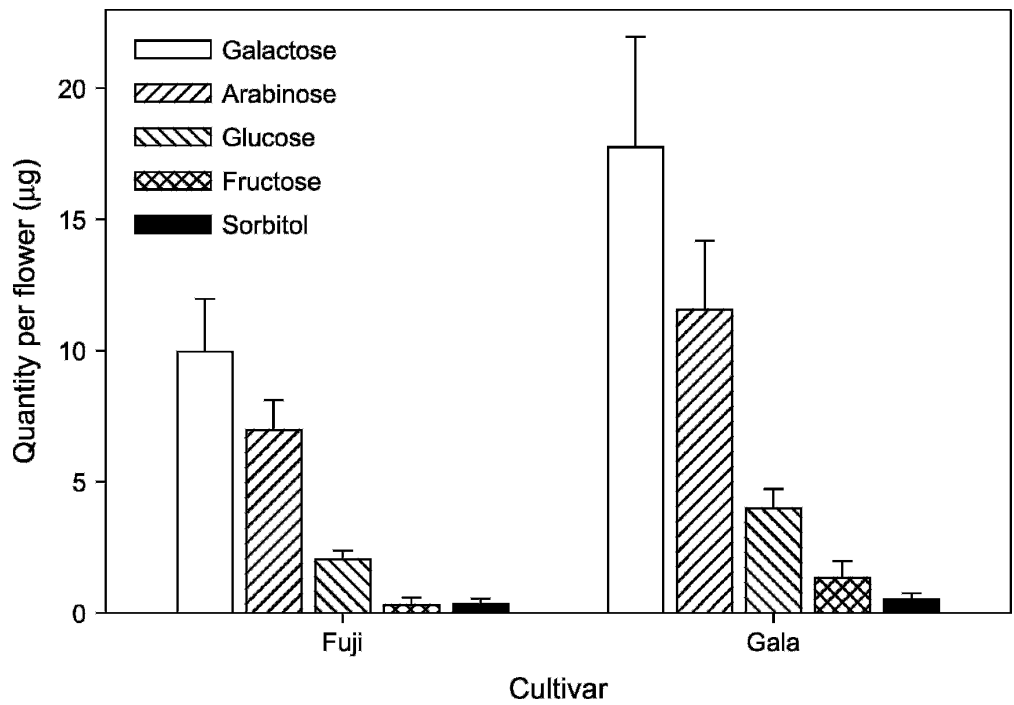

Fig. 6. Sugars detected in hydrolyzed samples of stigma exudates from 'Fuji' and 'Gala' apple (Malus communis). Each bar represents mean $( \pm \mathrm{SE})$ of five samples, each derived from 50 flowers. increasing their consumption of sugar. The period of anthesis, beginning at petal expansion and typically lasting 3 to $5 \mathrm{~d}$ depending on temperature, is about the period when stigmas are most conducive to bacterial colonization and growth (Pusey and Curry, 2004). The levels of free amino acids extracted per flower are not sufficient alone as sources of nitrogen for microbial growth but may be indicative of primary amino acids available from proteins through enzymatic action.

Another example of the applicability of this information to microbial activity on stigmas relates to the interaction between E. amylovora, the fire blight bacterium, and Pantoea agglomerans [Syn. Erwinia herbicola (Löhnis) Dye], another naturally occurring epiphytic bacterium on stigmas. Strains of the latter species have been studied extensively for potential use in biological control (Epton et al., 1994; Johnson and Stockwell, 2000; Vanneste, 1996), and three commercial products consisting of the live bacteria are now available or approved for fire blight in North America (Steinwand and Brohm, 2006; U.S. Environmental Protection Agency, 2006a, 2006b) and New Zealand (Vanneste et al., 2002). In addition to competing with E. amylovora for space and nutrients on stigmatic surfaces, these bacteria produce antibiotic compounds that inhibit the disease organism. The antibiotics of $P$. agglomerans are diverse and frequently deactivated by certain amino acids, particularly histidine (Ishimaru et al., 1988; Vanneste et al., 1992; Wodzinski and Paulin, 1994). The present study revealed which amino acids (if any, since all free amino acids were detected at very low levels) may be a factor affecting antibiotic activity and showed that histidine is absent or barely detectable. Conversely, nutrient compounds available to microorganisms can also enhance the production and activity of secondary metabolites. Pantoea agglomerans strain E325, selected based on screening bioassays with flowers (Pusey, 1997), produces an inhibitory compound exhibiting high specificity toward E. amylovora (P.L. Pusey, unpublished data). Production of the inhibitor in vitro was substantially greater when sugars and amino acids identified as exudate constituents were available than when other nutrient sources were present.

Knowledge of chemical components in stigma exudates of pomaceous flowers opens up the possibility of studying epiphytic organisms on synthetic media that are more comparable chemically to the microenvironment on the stigma. Such investigations could lead to a greater understanding of plant-microbe and microbe-microbe interactions. It may even have application in studies of pollen-tube growth. Sucrose has conventionally been used in pollen viability studies for pomaceous species (Flachowsky et al., 2007; Köpcke et al., 2002; Tiwari and Polito, 1988), but in some cases, use of the monosaccharides, glucose and fructose, may be more appropriate or realistic. 
Table 1. Summary of major chemical components of stigma exudates from 'Fuji' and 'Gala' cultivars of apple (Malus pumila) obtained by aqueous extraction when flowers were at $40 \%$ to $60 \%$ anther dehiscence ${ }^{2}$.

\begin{tabular}{|c|c|c|c|c|c|}
\hline \multirow[b]{2}{*}{ Category } & \multirow[b]{2}{*}{ Major subcomponents } & \multicolumn{2}{|c|}{ Fuji } & \multicolumn{2}{|c|}{ Gala } \\
\hline & & $\begin{array}{l}\text { Mass extracted } \\
\text { per flower }(\mu \mathrm{g})\end{array}$ & Percent of total & $\begin{array}{l}\text { Mass extracted } \\
\text { per flower }(\mu \mathrm{g})\end{array}$ & Percent of tota \\
\hline Free sugars & Glucose, fructose & $2.9(0.2)$ & 8.2 & $1.7(0.01)$ & 2.7 \\
\hline Free amino acids & ASN, GLN, GLU, PRO, SER & $<10^{-6}$ & $<10^{-5}$ & $<10^{-6}$ & $<10^{-6}$ \\
\hline Protein & - & $15.21(1.8)$ & 43.7 & $29.4(5.0)$ & 45.6 \\
\hline Lipids & - & $\mathrm{ND}^{\mathrm{x}}$ & ND & ND & ND \\
\hline
\end{tabular}

${ }^{2}$ Values are means $(n=2-9)$ with SE in parentheses.

${ }^{y}$ Polysaccharide quantities were estimated by subtracting total free sugar from total sugar in hydrolyzed samples.

${ }^{\mathrm{x}}$ Lipids were not detected using the gas chromatography analysis procedure of Moss (1981).

The current report involving apple and pear may be the first to provide a chemical characterization of rosaceous stigma exudates that includes the identification of specific free sugars, free amino acids, and polysaccharide subcomponents. It also reveals that certain sugars and amino acids are consistently predominant and increase during anthesis. This basic information not only relates to reproduction within an agriculturally important plant group, but should be useful in understanding the microbial interactions affecting disease development.

\section{Literature Cited}

Beattie, G.A. and S.E. Lindow. 1994. Comparison of the behavior of epiphytic fitness mutants of Pseudomonas syringae under controlled and field conditions. Appl. Environ. Microbiol. 60:3799-3808.

Bieleski, R.L. and R.J. Redgwell. 1980. Sorbitol metabolism in nectaries from flowers of Rosaceae. Aust. J. Plant Physiol. 7:15-25.

Bradford, M.M. 1976. A refined and sensitive method for the quantitation of microgram quantities of protein utilizing the principle of protein-dye binding. Anal. Biochem. 72:248254.

Campbell, R.J., R.D. Fell, and R.P. Marini. 1990. Characterization of apple nectar sugars in selected commercial and crab apple cultivars. Fruit Var. J. 44:136-141.

Certal, A.C., A.M. Sanchez, H. Kokko, W. Broothaerts, M.M. Oliveira, and J.A. Feijo. 1999. S-RNases in apple are expressed in the pistil along the pollen tube growth path. Sex. Plant Reprod. 12:94-98.

Cheung, A.Y. and H.M. Wu. 1999. Arabinogalactan proteins in plant sexual reproduction. Protoplasma 208:87-98.

Cresti, M., F. Ciampolini, and S. Sansavini. 1980. Ultrastructural and histochemical features of pistil of Malus communis: The stylar transmitting tissue. Scientia Hort. 12:327-337.

Epton, H.A.S., M. Wilson, S.L. Nicholson, and D.C. Sigee. 1994. Biological control of Erwinia amylovora with Erwinia herbicola, p. 335-352. In: Blakeman, J.P. and B. Williamson (eds.). Ecology of plant pathogens. CAB International, Wallingford, UK.

Flachowsky, H., A. Peil, T. Sopanen, Q. Elo, and V. Hanke. 2007. Overexpression of BpMADS4 from silver birch (Betula pendula Roth.) induces early-flowering in apple (Malus $\times$ domestica Borkh.). Plant Breed. 126:137-145.

Gane, A.M., D. Craik, S.L.A. Munro, G.J. Howlett, A.E. Clarke, and A. Bacic. 1995. Structural analysis of the carbohydrate moiety of arabinogalactan-proteins from stigmas and styles of Nicotiana alata. Carbohydr. Res. 277:67-85.
Gleeson, P.A. and A.E. Clarke. 1979. Structural studies on the major component of Gladiolus style mucilage, an arabinogalactan-protein. Biochem. J. 181:607-621.

Goubet, F., P. Jackson, M.J. Deery, and P. Dupree. 2002. Polysaccharide analysis using carbohydrate gel electrophoresis: A method to study plant cell wall polysaccharides and polysaccharide hydrolases. Anal. Biochem. 300:5368.

Herbert, P., P. Barros, N. Ratola, and A. Alves. 2000. HPLC determination of amino acids in musts and port wine using OPA/FMOC derivatives. J. Food Sci. 65:1130-1133.

Heslop-Harrison, J. 1976. A new look at pollination. Report of East Malling Research Station 1975:141-156.

Heslop-Harrison, Y. 2000. Control gates and micro-ecology: The pollen-stigma interaction in perspective. Ann. Bot. (Lond.) 85:5-13.

Horning, M.G., A.M. Moss, and E.C. Horning. 1968. Formation and gas-liquid chromatographic behavior of isometric steroid ketone methoxime derivatives. Anal. Biochem. 22:284-294.

Ishimaru, C.A., E.J. Klos, and R.R. Brubaber. 1988. Multiple antibiotic production by Erwinia herbicola. Phytopathology. 78:746-750.

Ishimizu, T., Y. Sato, T. Saito, Y. Yoshimura, S. Norioka, T. Nakanishi, and F. Sakiyama. 1996. Identification and partial amino acid sequences of seven S-RNases associated with self-incompatibility of Japanese pear, Pyrus pyrifolia Nakai. J. Biochem. (Tokyo) 120:326-334.

Johnson, K.B., T.L. Sawyer, and T.N. Temple. 2006. Rates of epiphytic growth of Erwinia amylovora on flowers common in the landscape. Plant Dis. 90:1331-1336.

Johnson, K.B. and V.O. Stockwell. 1998. Management of fire blight: A case study in microbial ecology. Annu. Rev. Phytopathol. 36:227-248.

Johnson, K.B. and V.O. Stockwell. 2000. Biological control of fire blight, p. 319-337. In: Vanneste, J.L. (ed.). Fire blight; The disease and its causative agent, Erwinia amylovora. CAB International, Wallingford, UK.

Johnson, K.B., V. Stockwell, D.M. Burgett, D. Sugar, and J.E. Loper. 1993. Dispersal of Erwinia amylovora and Pseudomonas fluorescens by honey bees from hives to apple and pear blossoms. Phytopathology 83:478-484.

Kandasamy, M.K. and M. Vivekanandan. 1986. Stigmatic exudate: Its origin, physical nature, biochemical composition and function. Indian Rev. Life Sci. 6:1-17.

Keitt, G.W. and S.S. Ivanoff. 1941. Transmission of fire blight by bees and its relation to nectar concentration of apple and pear blossoms, J. Agr. Res. 62:745-753.

Knox, R.B. 1984. Pollen-pistil interactions, p 508-608. In: Linskens, H.F. and J. HeslopHarrison (eds.). Cellular interactions. SpringerVerlag, New York, NY.
Köpcke, D., P. Baur, and J. Schönherr. 2002 Inhibition of the growth of apple pollen tubes by EDTA, surfactants and fungicides. Ann. Appl. Biol. 140:81-86.

Kristen, V., M. Biedermann, G. Liebezeit, R. Dawson, and L. Böhm. 1979. The composition of stigmatic exudates and the ultrastructure of the stigma papillae in Aptenia cordifolia. Eur. J. Cell Biol. 19:281-287.

Mateo, R., F. Bosch, and A. Pastor. 1987. Capillary column gas chromatographic identification of sugars in honey as trimethylsilyl derivatives. J. Chromatogr. 410:319-328.

McClure, B.A. and V. Franklin-Tong. 2006. Gametophytic self-incompatibility: Understanding the cellular mechanisms involved in 'self' pollen tube inhibition. Planta 224:233245.

Moss, C.W. 1981. Gas-liquid chromatography as an analytical tool in microbiology. J. Chromatogr. 203:337-347.

Nishio, T. and K. Hinata. 1979. Purification of an Sspecific glycoprotein in self-incompatible Brassica campestris L. Jpn. J. Genet. 54:307-311.

Pusey, P.L. 1997. Crab apple blossoms as a model for research on biological control of fire blight. Phytopathology 87:1096-1102.

Pusey, P.L. 1999a. Effect of nectar on microbial antagonists evaluated for use in control of fire blight of pome fruits. Phytopathology 89:39-46.

Pusey, P.L. 1999b. Laboratory and field trials with selected microorganisms as biocontrol agents for fire blight. Acta Hort. 489:655661.

Pusey, P.L. 2000. The role of water in epiphytic colonization and infection of pomaceous flowers by Erwinia amylovora. Phytopathology 90:1352-1357.

Pusey, P.L. and E.A. Curry. 2004. Temperature and pomaceous flower age related to colonization by Erwinia amylovora and antagonists. Phytopathology 94:901-911.

Sanzol, J., P. Rallo, and M. Herrero. 2003. Asynchronous development of stigmatic receptivity in the pear (Pyrus communis; Rosaceae) flower. Amer. J. Bot. 90:78-84.

Sato, Y., T. Saito, Y. Yoshimura, S. Norioka, T. Nakanishi, and F. Sakiyama. 1996. Identification and partial amino acid sequences of seven S-RNases associated with selfincompatibility of Japanese pear, Pyrus pyrifolia Nakai. J. Biochem. (Tokyo) 120:326-334.

Sonneveld, T., K.R. Tobutt, S.P. Vaughan, and T.P. Robbins. 2005. Loss of pollen-S function in two self-compatible selections of Prunus avium is associated with deletion/mutation of an $\mathrm{S}$ haplotype-specific F-box gene. Plant Cell 17:37-51.

Stant, M.Y. 1981. Stigma investigations in Malus. Micron 12:179-180.

Steinwand, B. and M. Brohm. 2006. Joint review of microbials, and pheromones and 'other' 
biopesticides. Project Sheet of Risk Reduction Subcommittee of NAFTA Technical Working Group on Pesticides, Project ID RR04-99-1105. 4 Apr. 2008. <http://www.pmra-arla.gc.ca/ english/pdf/nafta/risk/RR04-99-1105-e.pdf $>$.

Stockwell, V.O., R.J. McLaughlin, M.D. Hendels, J.E. Loper, D. Sugar, and R.G. Roberts. 1999. Epiphytic colonization of pear stigmas and hypanthia by bacteria during primary bloom. Phytopathlogy 89:1162-1168.

Thomson, S.V. 1986. The role of the stigma in fire blight infections. Phytopathology 76:476482.

Thomson, S.V., D.R. Hansen, K.M. Flint, and J.D. Vandenberg. 1992. Dissemination of bacteria antagonistic to Erwinia amylovora by honey bees. Plant Dis. 76:1052-1056.

Tiwari, S.C. and V.S. Polito. 1988. Spatial and temporal organization of actin during hydration, activation, and germination of pollen in Pyrus communis L.: A population study. Protoplasma 147:5-15.
U.S. Environmental Protection Agency. 2006a Pantoea agglomerans strain C9-1; exemption from the requirement of a tolerance. EPA, Washington, DC. Fed. Regist. 71:24590-24596.

U.S. Environmental Protection Agency. 2006b. Pantoea agglomerans strain E325; exemption from the requirement of a tolerance. EPA, Washington, DC. Fed. Regist. 71:5492854933.

Uwate, W.J. and J. Lin. 1981. Development of the stigmatic surface of Prunus avium L., sweet cherry. Amer. J. Bot. 68:1165-1176.

van der Zwet, T. and H.L. Keil. 1979. Fire blight: A bacterial disease of rosaceous plants. Agric. Handb. 510. U.S. Dep. Agric. Sci. Educ. Admin. Vanneste, J.L. 1996. Honey bees and epiphytic bacteria to control fire blight, a bacterial disease of apple and pear. Biocontrol News Info. $17: 67 \mathrm{~N}-78 \mathrm{~N}$

Vanneste, J.L., D.A. Cornish, J. Yu, and M.D. Voyle. 2002. P10c: A new biological control agent for control of fire blight which can be sprayed or distributed using honey bees. Acta Hort. 590:231-235.

Vanneste, J.L., J. Yu, and S.V. Beer. 1992. Role of antibiotic production by Erwinia herbicola Eh252 in biological control of Erwinia amylovora. J. Bacteriol. 174:27852796.

Wodzinski, R.S. and J.P. Paulin. 1994. Frequency and diversity of antibiotic production by putative Erwinia herbicola strains. J. Appl. Bacteriol. 76:603-607.

Wolters-Arts, M., W.M. Lush, and C. Mariani. 1998. Lipids are required for directional pollentube growth. Nature 392:818-820.

Wu, H., B. de Graaf, C. Mariani, and A.Y. Cheung. 2001. Hydroxyproline-rich glycoproteins in plant reproductive tissues: Structure, functions and regulation. Cell. Mol. Life Sci. 58:14181429.

Wykes, G.R. 1952. An investigation of the sugars present in the nectar of flowers of various species. New Phytol. 51:210-215. 